\title{
Genetic tests for athletic ability: Science or snake oil?
}

$\mathrm{T}$

homas Reynolds has grown tired of being called a peddler of high-tech snake oil. In the field of direct-to-consumer genetic testing, however, critics abound - especially when those tests are for assessing something as complex as athletic potential.

"The intellectuals really want to control this information. They don't want people to have their genetic information. But people can fathom the information. They can process it, even if they may not be leaders in molecular biology at Harvard [University in Boston, Massachusetts]," says Reynolds, vice president of science and technology for AIBioTech, a biotechnology services company located in Richmond, Virginia. "We use the latest and greatest technology, and I feel very strongly that we are providing a valuable service to people."

In June, AIBioTech launched Sports $\mathrm{X}$ Factor, a suite of direct-to-consumer genetic tests to assess athletic performance characteristics and risk factors for athletes. An indicator of an athlete's potential to excel in a particular sport is based on tracking genetic markers associated with speed/power or endurance.

Other genetic markers are tracked to assess if athletes are predisposed to particular health risks, including arrhythmia, slow recovery from concussions and hypertrophic cardiomyopathy, a thickening of the heart muscle and the leading cause of sudden cardiac deaths in young athletes.

"There are a number of these guys who just collapse from a condition that is aggravated by strenuous training or strenuous exercise," says Reynolds, referring to hypertrophic cardiomyopathy. "It's not because they over-trained or because they're taking drugs. This is a genetic disease. It affects a small amount of people, around 1 in 500, so it's uncommon but is common enough."

A basic set of tests to measure these risk factors and the speed/power and endurance markers cost US\$200. For just under US $\$ 1000$, a consumer can purchase the full panel of tests, which

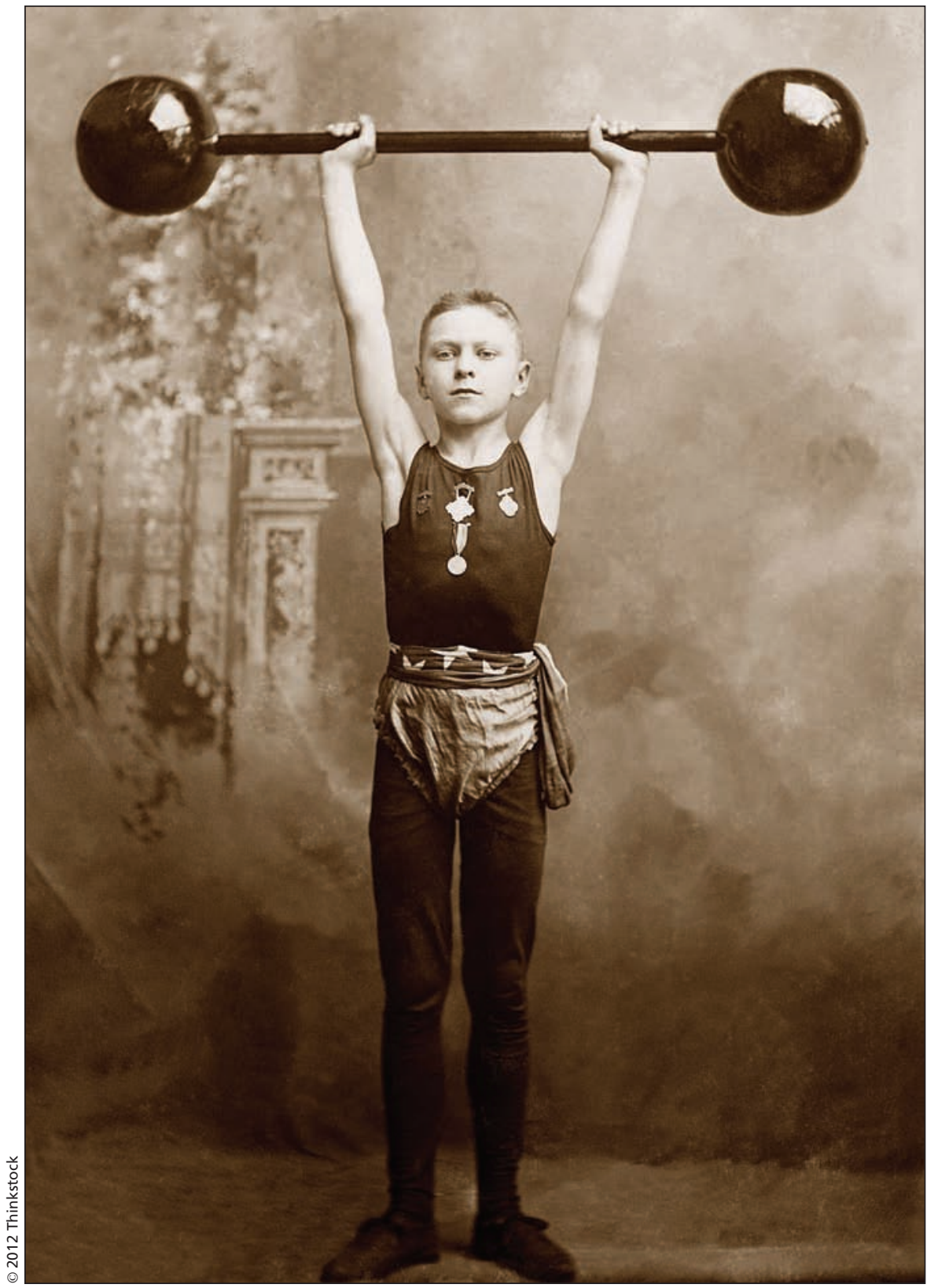

Direct-to-consumer genetic tests for athletic ability hope to identify a child's predisposition to excel in different sports.

also includes ones for tracking markers associated with soft-tissue injuries, iron absorption and other cardiac problems.

The United States Food and Drug Administration has not yet slapped a stamp of approval on Sports X Factor, though it has met with AIBioTech, which is conducting more research at the regulator's request. "Had it gone through a medical doctor, it wouldn't be an issue," says Reynolds. "But because we are selling directly to consumers, they have some concerns."

AIBioTech is not the first company to offer genetic tests for sports. In 2008, Atlas Sports Genetics, based in Boulder, 
Colorado, began selling the Atlas First SportGene Test. It focused on one particular gene: ACTN3, the so-called "speed gene." The company claims research has shown a link between a particular mutation of this gene, which affects muscle fibres, and an individual's predisposition to perform better in speed/power sports, such as football, or endurance sports, such as distance running.

But this is a gross over-simplification of the science, according to many critics of these types of consumer genetic tests, including Timothy Caulfield, a Canada Research Chair in Health Law and Technology. "There are so many factors that contribute to something as complex as performance in sports that it seems ridiculous to narrow it down to this one type of genetic test," he says.

For Caulfield, who teaches in the law faculty and school of public health at the University of Alberta in Edmonton, the effect of genetics on athletic performance is an area of particular interest. $\mathrm{He}$ has been a sprinter his entire life and at one point even had dreams of making it to the Olympics. He recently concluded that there is more hype than substance to direct-to-consumer genetic tests, including those for sports (JCOM 2011;10:C02).

In his paper, Caulfield divided the tests into three categories. There are the "clearly preposterous" tests that have no solid science to back them, including tests to develop personalized perfumes, create customized diet plans and help you find a genetically compatible mate. Then there are companies that sell "vaguely predictive" tests that provide valid genetic data but mislead consumers by vastly overstating the value to their health of possessing that information.

The third category of tests, which Caulfield dubbed "marginally pertinent," are based on solid science but are marketed as testing for something far greater in complexity than is currently possible.
A test for athletic ability based on the ACTN3 gene would fall into this category, wrote Caulfield. "While this gene is related to the regulation of fast-twitch muscle fibres, it is wrong to imply that it is a test for athletic ability, a complex, socially constructed and multi-factorial concept, or that it can provide anything close to a definitive conclusion about future speed abilities."

One of the most commonly cited research papers to support genetic testing in sports is a 2003 study of the ACTN3 genes in elite-level sprinters conducted by medical researchers in Australia, which suggested that genetic research shows an "evolutionary 'trade-off' between performance traits for speed and endurance activities" (Am J Hum Genet 2003;73:627-31). Still, it's "absurd" to even suggest that tests designed to prey on "the anxieties and gullibility of parents who have no biomedical training and are irrationally desperate to achieve success for their children" can help average athletes maximize their athletic potential, according to an editorial by Dr. David Nathan and Dr. Stuart Orkin, researchers at the Dana-Farber Cancer Institute in Boston, Massachusetts (Genome Medicine 2009;1:I8).

"We consider conclusions drawn from single genetic tests to establish probabilities of complex traits both foolish and venial: venial because the hucksters and mountebanks who promote the tests do so knowing that they are selling snake oil," the editorial states.

Indeed, the primary problem in the field of genetic testing is that the marketing is leading the research, says Kerry Bowman, a bioethicist at the University of Toronto Joint Centre for Bioethics in Ontario. The role of genetics in athletic performance is not yet well understood, he says, and success in sports is affected by many factors, including what can best be described as pure grit.

"The assumptions in the marketing are highly premature," says Bowman. "One of the problems is that as genomics evolves, it's being pushed very heavily by market forces, and it's eroding public confidence.

Of course, marketers might have difficulty attenuating the hype because, according to some academics, genetic tests for sports aren't useful anyway.

The trained eye has more predictive value than a genetic test, says Michael McNamee, a professor in the Department of Philosophy, Humanities and Law in Healthcare in the College of Human and Health Sciences at Swansea University in the United Kingdom.

"It's just hype as far as I can see," says McNamee, who has questioned the validity of expanding the role of genetic testing beyond traditional medical aims into the realm of sports performance (Sports Med 2009: 39:339-44). "If you want to see if someone is going to be a good sprinter, watch them. An educated observer can tell you more than a genetic test."

Reynolds counters that accusations that his firm and others are only out to reap big profits are entirely ridiculous, because there isn't much money to be made in this area. "The overall market is pretty small. We are not doing it for the reasons some people think. It's not a greed-base activity," says Reynolds, adding that AIBioTech is no fly-bynight operation. "We've been around since 1992. We plan on being around in another 20 years." - Roger Collier, CMAJ

CMAJ 2012. DOI:10.1503/cmaj.109-4063

Editor's note: First of a two-part series.

Part II: Testing the ethics of genetic testing in sports

(www.cmaj.ca/lookup/doi/10.1503

/cmaj.109-4064). 